\title{
Management and Outcomes of Isolated Distal Deep Vein Thromboses: A Questionable Trend toward Long-Lasting Anticoagulation Treatment. Results from the START-Register
}

\author{
Gualtiero Palareti ${ }^{1}$ Cristina Legnani ${ }^{1}$ Emilia Antonucci ${ }^{1}$ Sophie Testa ${ }^{2}$ Daniela Mastroiacovo ${ }^{3}$ \\ Benilde Cosmi ${ }^{4}$ Daniela Poli ${ }^{5}$ Eugenio Bucherini ${ }^{6}$ Francesco Dentali ${ }^{7}$ Andrea Fontanella ${ }^{8}$ \\ Nicola Mumoli ${ }^{9(1)}$ Davide Imberti $^{10}$ Anna Falanga ${ }^{11}$ (i) Walter Ageno ${ }^{12}$ Fulvio Pomero ${ }^{13}$
}

${ }^{1}$ Arianna Anticoagulazione Foundation, Bologna, Italy

${ }^{2}$ Centro Emostasi e Trombosi A O Istituti Ospitalieri di Cremona, Cremona, Italy

${ }^{3}$ Daniela Mastroiacovo MD, Dipartimento di Angiologia, Ospedale SS. Filippo e Nicola, Avezzano, (L'Aquila), Italy

${ }^{4}$ Department of Angiology and Blood Coagulation, University Hospital, Bologna, Italy

${ }^{5}$ SOD Malattie Aterotrombotiche, Azienda Ospedaliero Universitaria-Careggi, Firenze, Italy

${ }^{6}$ SS Aziendale di Angiologia Faenza AUSL Romagna, Ravenna, Italy

${ }^{7}$ Dipartimento di Medicina Interna, Ospedale di Circolo, Università dell'Insubria, Varese, Italy

${ }^{8}$ Dir. Dipartimento di Medicina, Ospedale del Buon ConsiglioFatebenefratelli, Napoli, Italy

${ }^{9}$ Department of Internal Medicine, Magenta Hospital, Magenta (MI), Italy

10 UO Medicina Interna ERI, Ospedale Civile, Piacenza, Italy

11 Università Milano Bicocca, Dipartimento di Medicina e Chirurgia, Italy

12 UOC Immunoematologia e Medicina Trasfusionale ASST Bergamo, Italy

13 Dipartimento di Emergenza e Accettazione, Centro Trombosi ed Emostasi, Ospedale di Circolo, Università dell'Insubria, Varese, Italy
Address for correspondence Gualtiero Palareti, MD, "Arianna Anticoagulazione” Foundation, Via Paolo Fabbri, 1/3, 40138, Bologna, Italy (e-mail: Gualtiero.palareti@unibo.it).

\section{Abstract \\ Keywords \\ - isolated distal deep vein thrombosis \\ - oral anticoagulant \\ - bleeding \\ - duration of treatment}

Background Isolated distal deep vein thromboses (IDDVT) are frequently diagnosed; however, their natural history and real risk of complications are still uncertain. Though treatment is still not well standardized, international guidelines recommend no more than 3 months of anticoagulation therapy. We investigated how Italian clinicians treat IDDVT patients in their real life in our country.

Methods Baseline characteristics and clinical history of the patients enrolled in the prospective, observational, multicenter START-Register for a first IDDVT or proximal DVT (PDVT) were analyzed.

Results Overall, 412 IDDVT patients were significantly younger, with better renal function, and more frequent major transient risk factors, when compared with 1,173 PDVT patients. The anticoagulation duration was $>180$ days in $52.7 \%$ of IDDVT patients received

February 5, 2021

accepted after revision

April 12, 2021
DOI https://doi.org/

$10.1055 / \mathrm{s}-0041-1730038$. ISSN 2512-9465. (c) 2021. The Author(s).

This is an open access article published by Thieme under the terms of the Creative Commons Attribution License, permitting unrestricted use, distribution, and reproduction so long as the original work is properly cited. (https://creativecommons.org/licenses/by/4.0/)

Georg Thieme Verlag KG, Rüdigerstraße 14, 70469 Stuttgart, Germany 
(70.7\% in PDVT). During treatment, bleeding occurred in 5.6 and $2.8 \%$ patient-years in IDDVT and PDVT, respectively $(p=0082)$. Bleeding was more frequent in IDDVT than PDVT patients treated with warfarin (6.8 vs. 3.2 patient-years, $p=0.0228$, respectively). Thrombotic complications occurred in 1.1 and $2.4 \%$ patient-years in IDDVT and PDVT patients, respectively. Analyzing together the two groups, $66.1 \%$ of bleeds and $86.1 \%$ thrombotic complications occurred after 90 days anticoagulation treatment. Conclusion The large majority of IDDVT patients received anticoagulation for more than 3 months. Most bleeding and thrombotic complications occurred after the first 90 days of anticoagulation therapy. These results indicate that an extended anticoagulation beyond 90 days in IDDVT patients is associated with increased risk of complications. Whether an extended treatment may lower recurrences after anticoagulation withdrawal should be assessed by specifically designed studies.

\section{Introduction}

Isolated distal deep vein thrombosis (IDDVT) generally refers to a thrombotic process that affects one or more of the deep calf veins (either axial or muscular) but does not involve the popliteal or more proximal veins (PDVT). The presence of IDDVT is a frequent finding in patients with suspected DVT; however, its prevalence in suspected patients varies greatly, ${ }^{1}$ mainly due to the possible adoption of different ultrasound diagnostic procedures which may be limited to just proximal deep veins or else extend to calf veins (thus potentially able to identify distal DVTs). ${ }^{2}$ Once IDDVTs are diagnosed, their optimal treatment is far from being standardized and longterm clinical outcomes unclear. ${ }^{3}$ For this disease, heparin or derivatives (especially low molecular weight heparin [LMWH]), vitamin-K antagonists (VKAs), and direct oral anticoagulants (DOACs) can be used for therapy. Currently, however, optimal treatment has still not been adequately standardized: anticoagulant of choice, appropriate dosing, and duration of treatment are still a matter of discussion. This state of affairs, in large part, can be put down to a general lack of interest by researchers in the disease, as witness the literature which has been persistently much less than that on proximal DVT or pulmonary embolism. ${ }^{4}$ Given the relative paucity of randomized clinical trials, prospective observational studies can give us important information on clinicians' approach to diagnosis, management, and treatment of IDDVT.

The present study aimed at analyzing the therapeutic approach of Italian clinicians to patients diagnosed with acute IDDVT, as first venous thrombotic episode, who were included in the prospective, observational, multicenter START-VTE-Registry. Their baseline characteristics, type of management, and clinical results were analyzed and compared with those recorded in patients included in the registry for a first event that was proximal DVT of a lower limb.

\section{Materials and Methods}

\section{The START-Register}

The START-Register (ClinicalTrials.gov identifier: NCT02219984) is an observational, multicenter, dynamic cohort study of adults ( $\geq 18$ years) starting anticoagulation therapy, whatever the indication for treatment and drug/dosage used. $^{5}$ The present article reports only on patients included in the registry for a first venous thrombotic event due to IDDVT or proximal DVT (PDVT). Authorization to set up the START-Register was obtained from the Ethical Committee of the University Hospital "S. Orsola-Malpighi," Bologna, Italy, on October 2011 (no.: 142/2010/0/0ss") which is entrusted with the deployment and upkeep of the registry central database. The registry is one of the activities of the "Arianna Anticoagulazione" Foundation (Bologna, Italy). The registry is open to all physicians (called participants) prescribing anticoagulant or antithrombotic therapy who agree to the registry protocol. Participants should obtain approval from their local institution review board and are required to enroll their patients consecutively or randomly, with no exclusion criteria other than obstacles for follow-up (short life-expectancy or geographical inaccessibility). Participants enroll patients only after receiving their informed consent. The participating centers are required to enroll their patients consecutively, without any a priori exclusion criteria other than life-expectancy or geographical inaccessibility. Definition of the time frame for enrolment (e.g., 1 week every month or the first month of the year) is left at each participant's discretion, as long as it provides a random enrolment of patients. The accuracy and completeness of the data collected anonymously in the central electronic database are checked by a trained and dedicated monitor figure who also solicits participating centers to contact, for the purpose of this study, patients lost to follow-up either by a telephone call or through their General Practitioner. The study was performed and is reported according to the Strengthening the Reporting of Observational Studies in Epidemiology (STROBE) guidelines for observational studies. ${ }^{6}$

\section{Study Population}

All patients with clinical indications of DVT and/or pulmonary embolism (PE) were registered in the START-Register, including the FADOI-START-Register (which is a subportion of the START-Register dedicated to VTE patients included by centers 
affiliated with the Italian FADOI Federation ["Federazione delle Associazioni dei Dirigenti Ospedalieri Internisti"]).

The present study focused on patients included in the START-Register for October 2010 up to June 2018 for a first episode of IDDVT or of PDVT of a lower limb; their baseline characteristics, anticoagulation management, and clinical results were compared. We limited the study to patients whose VTE event was the first in their life since our focus was on the type of treatment decision taken in patients with no VTE history. Patients included in the registry for a PE event (either in isolation or associated with PDVT or IDDVT) were also excluded from the study, since this condition is generally considered a more serious disease that is likely to have an influence on the therapeutic approach of treating physicians. The treatments and the events occurring during follow-up were then analyzed in IDDVT and PDVT patients. LMWHs, fondaparinux, and warfarin (the VKA used in approximately $99 \%$ of considered patients) were always available as anticoagulant drugs for therapy during the observation period, whereas DOACs have only been allowed and reimbursed by the National and Regional Health Systems for initial, long term and extended anticoagulant treatment for patients with venous thromboembolism (VTE; including IDDVT) since January 2014.

\section{Data Collection}

Participants in the START-Register connect to the central electronic database via web using individual passwords. Information is recorded in structured case report form (CRF) and involves baseline characteristics of included patients and their follow-up. Baseline characteristics of patients included in the present study were (1) demographic, body weight, routine laboratory data, and past medical history (hypertension, diabetes mellitus, heart failure, coronary arteries disease, peripheral arteries disease, atrial fibrillation, previous stroke or transient ischemic attack or systemic embolism, chronic pulmonary disease, gastrointestinal disease, thyroid disease, previous clinically relevant bleeding, malignancy, renal and liver function, and alcohol abuse); (2) characteristics of index VTE event and presence of risk factors; (3) anticoagulant agents used, dosages, or the intended therapeutic range (2.0-3.0 international normalized ratio [INR] in all cases receiving VKAs), concomitant medications (especially antiplatelet drugs).

Serum creatinine levels were measured by local hospital laboratories and creatinine clearance $(\mathrm{CrCl})$ calculated by the Cockcroft and Gault equation. ${ }^{7}$ Renal failure was defined according to National Kidney Foundation stratification. ${ }^{8}$

Information was collected about the nature and site of VTE events. The nature of index event was considered as follows: (1) unprovoked, when not temporally associated with any potential triggering conditions or risk factors (RF); (2) associated with weak RF, such as minor, arthroscopic or laparoscopic general surgery, pregnancy or puerperium, contraceptive or replacement hormonal therapy, long trip, minor trauma, stay in hospital, and reduced mobility (not complete immobilization); (3) provoked by transient major $\mathrm{RF}$ when in association with one of the following conditions occurring within 3 months of VTE diagnosis: major surgery with general or spinal anesthesia, lower limb fracture, casting or no weight bearing for $\geq 3$ days, bed-bound for $>3$ days due to acute illness, and others; (4) provoked by permanent major RF, when associated with active cancer, paraplegia, chronic active inflammatory disease (e.g., intestinal inflammatory disease) or other chronic serious diseases, serious inherited thrombophilic alterations, antiphospholipid syndrome, severe postthrombotic syndrome, and presence of cava filter.

For the present analysis, the site of events was classified in (1) cases with IDDVT, when thrombosis involved only calf veins and was not associated with diagnosis of PE; or (2) PDVT, when thrombosis involved popliteal or onward deep veins (with or without calf DVT), without PE diagnosis. The patients included in the registry with $\mathrm{PE}$, with or without PDVT or IDDVT, were not included in the present analysis.

\section{Follow-up Data}

The present study reports on the events occurred in IDDVT and PDVT patients during their anticoagulant treatment. Follow-up was considered from inclusion of patients until December 2018, or until a permanent cessation of anticoagulant treatment, the last follow-up available in patients who subsequently were lost to follow-up or declined to further participate in the START-Register, or occurrence of major bleeding, thrombotic complications, death, whichever came first. During follow-up, detailed clinical reports of any relevant clinical outcome occurring in enrolled patients were collected. Major bleeding (MB), was defined according to International Society on Thrombosis and Haemostasis criteria. ${ }^{9}$ Clinically relevant nonmajor bleeding (CRNMB) events were defined as any overt bleeding requiring a medical intervention and/or treatment discontinuation, not meeting any of the criteria for major bleeding. ${ }^{10}$ Thromboembolic events were recorded and defined as verified events of either venous type (recurrent VTE episode, venous thrombosis in different sites, or superficial vein thrombosis) or arterial type (stroke/arterial thromboembolism/TIA or myocardial infarction).

\section{Statistical Analysis}

Continuous variables are expressed as median with interquartile range (IQR). Categorical variables are expressed as frequencies and percentages. The number of bleeding events was expressed as percentage (with $95 \%$ confidence intervals [CI]) and incidence rate and calculated as the number of events per 100 patient-years of observation. Differences between groups were assessed using the $\times 2$ test with Yates' correction for categorical variables and the Mann-Whitney $U$-test for continuous variables. The data were analyzed with the use of Prism software (Version 8.4.0, GraphPad Software Incorporated, San Diego, California, United States), and Stata, version 14 statistical software package (Stata Corp.) was used for data processing.

\section{Results}

As shown in -Fig. 1, from the 6,835 patients included in the START-Register up to June 2018 for occurrence of one or more venous thromboembolic events, 3,551 patients 


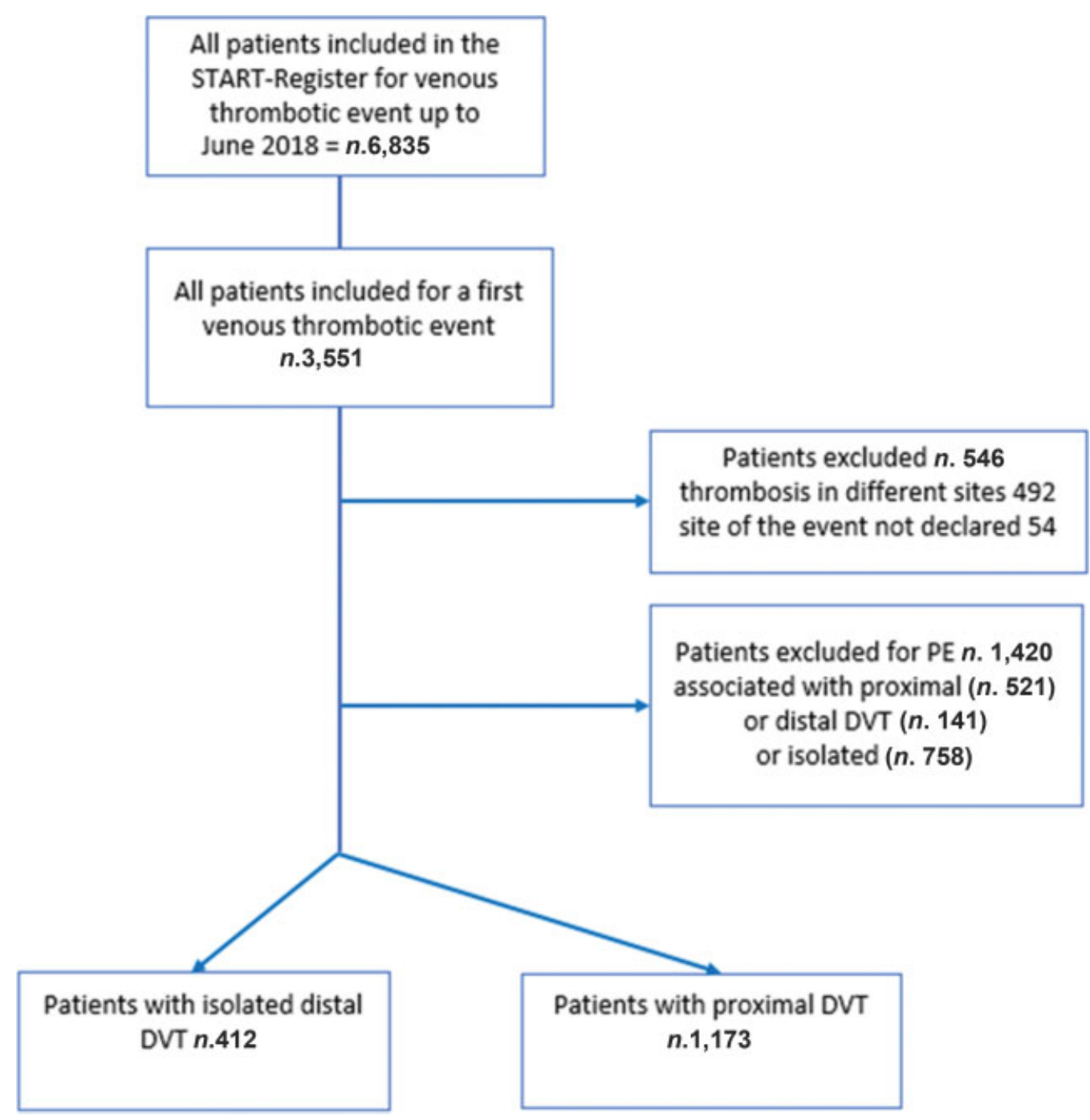

Fig. 1 Patient flowchart. DVT, deep vein thrombosis; isolated distal DVT: thrombosis of one or more calf deep veins not involving the popliteal vein; PDVT: DVT that involves the popliteal vein and/or more proximal deep veins (with or without distal DVT); PE: pulmonary embolism.

presenting first-in-life event were identified. After excluding 1,966 patients (492 for thrombosis in different sites, 54 because the site of the event was not reported, and 1,420 because the event was a PE), 412 patients with IDDVT were analyzed and compared with the 1,173 with PDVT who were enrolled in the START-Register by 51 clinical centers which on average included 26 patients (minimum $=3$, maximum $=301$ ).

\section{Baseline Characteristics of Patients}

At baseline ( - Table $\mathbf{1}$ ), patients with IDDVT versus PDVT were significantly younger with a lower presence of elderly ( $\geq 75$ years), had a generally better renal function, and a lower prevalence of so-called fragile conditions. The unprovoked or provoked nature of thrombotic events was equally distributed across the two groups of patients; however, major risk factors were more frequently transient in IDDVT $(p=0.0001)$ and permanent in PDVT $(p<0.0001)$. Less patients with IDDVT were fragile $(p=0.0002)$ or had chronic inflammatory diseases $(p=0.0237)$, whereas more of them were treated for hypertension ( $p=0.0193$ ). Users of lipid lowering drugs were more frequent among IDDVT $(p=0.0045)$.

Parenteral anticoagulation drugs (including LMWH or fondaparinux) were used in a small and similar proportion in IDDVT and PDVT patients ( 6\%). Warfarin and DOACs were prescribed in equal measure in IDDVT patients, whereas DOAC use was markedly higher and warfarin lower in PDVT patients (61.3 and 32.5\%, respectively). Among DOACs, rivaroxaban was the most frequently used drug, given it was the first in the category to be available for this indication (since 2014) and reimbursed by the Italian National Healthcare System. In both IDDVT and PDVT groups, the treatment was shortest in patients using parenteral anticoagulants and longest in those receiving warfarin ( $\mathbf{- T a b l e ~} \mathbf{1})$.

\section{Duration of Anticoagulation and Outcomes during Treatment}

As reported in -Table 2, less than one-fourth (22.3\%) of IDDVT patients received anticoagulation treatment up to 90 days, and more than half $(52.7 \%)$ were treated for $>180$ days. About $29 \%$ of PDVT patients were treated for up to 
Table 1 Baseline characteristics of patients with a first event of IDDVT or PDVT

\begin{tabular}{|c|c|c|c|}
\hline$n$ & IDDVT $(n=412)$ & PDVT $(n=1,173)$ & $p$ \\
\hline Male, $n(\%)$ & $205(49.8)$ & $619(52.8)$ & 0.2945 \\
\hline $\begin{array}{l}\text { Age (y) } \\
\text { Median (IQR) }\end{array}$ & $65(49.2-75)$ & $69(53-79)$ & 0.0005 \\
\hline \multicolumn{4}{|l|}{$\begin{array}{l}\text { Age classes }(y) \\
n(\%)\end{array}$} \\
\hline$<60$ & $162(39.3)$ & $384(32.7)$ & 0.0153 \\
\hline $60-74$ & $140(34.0)$ & $356(30.3)$ & 0.1635 \\
\hline$\geq 75$ & $110(26.7)$ & $433(37.0)$ & 0.0002 \\
\hline $\begin{array}{l}\text { BMI }\left(\mathrm{kg} / \mathrm{m}^{2}\right) \\
\text { Missing }\end{array}$ & $\begin{array}{l}26(24-29) \\
3\end{array}$ & $\begin{array}{l}26(24-29) \\
9\end{array}$ & 0.7403 \\
\hline $\begin{array}{l}\text { First available creatinine } \\
\text { Median (IQR) }\end{array}$ & $0.90(0.70-1.00)$ & $0.90(0.80-1.00)$ & 0.0161 \\
\hline $\begin{array}{l}\text { Creatinine }>1.5 \mathrm{mg} / \mathrm{dL} \\
n(\%)\end{array}$ & $16(3.9)$ & $55(4.7)$ & 0.5002 \\
\hline \multicolumn{4}{|l|}{$\begin{array}{l}\mathrm{CrCl} \\
n(\%)\end{array}$} \\
\hline$<30 \mathrm{~mL} / \min$ & $9(2.2)$ & $29(2.5)$ & 0.7334 \\
\hline $30-59 \mathrm{~mL} / \mathrm{min}$ & 82 (19.9) & $321(27.4)$ & 0.0027 \\
\hline$\geq 60 \mathrm{~mL} / \mathrm{min}$ & 321 (77.9) & $821(70.1)$ & 0.0024 \\
\hline Missing & - & 3 & \\
\hline \multicolumn{4}{|l|}{$\begin{array}{l}\text { Nature of VTE events } \\
n(\%)\end{array}$} \\
\hline Unprovoked & $260(63.3)$ & $746(63.6)$ & 0.9134 \\
\hline Provoked & $151(36.7)$ & $427(36.4)$ & \\
\hline - By weak RFs & $24(16.0)$ & $53(12.4)$ & 0.2639 \\
\hline - By transient major RFs & $92(60.9)$ & $180(42.2)$ & 0.0001 \\
\hline - By permanent major RFs & $35(23.1)$ & $194(45.4)$ & $<0.0001$ \\
\hline - Cancer & $19(12.6)$ & $80(18.7)$ & 0.0874 \\
\hline - Missing & 1 & - & \\
\hline Diabetes & $35(8.5)$ & $118(10.1)$ & 0.3450 \\
\hline Hypertension & $115(27.9)$ & $260(22.2)$ & 0.0193 \\
\hline IHD, CVD, PAD & $60(14.6)$ & $174(14.8)$ & 0.9216 \\
\hline Heart failure & $11(2.7)$ & $35(3.9)$ & 0.2601 \\
\hline Chronic inflammatory dis & $44(10.7)$ & $178(15.2)$ & 0.0237 \\
\hline Known thrombophilia & $33(8.0)$ & $116(9.9)$ & 0.2559 \\
\hline Fragile (age $>75 \mathrm{y}$, or $\leq 50 \mathrm{~kg}$, or $\mathrm{CrCl}<50 \mathrm{~mL} / \mathrm{min}$ ) & $122(29.6)$ & $470(40.1)$ & 0.0002 \\
\hline \multicolumn{4}{|l|}{ Associated treatments } \\
\hline - Antiplatelet drugs & $35(8.5)$ & $89(7.6)$ & 0.5588 \\
\hline - Antiarrhythmic drugs & $7(1.7)$ & $23(2.0)$ & 0.7029 \\
\hline - Antidiabetics & $27(6.6)$ & $79(6.7)$ & 0.9442 \\
\hline - Lipid lowering drugs & $66(16.0)$ & $126(10.7)$ & 0.0045 \\
\hline \multicolumn{4}{|l|}{ Anticoagulation treatments } \\
\hline $\begin{aligned} \text { - } & \text { LMWHs } \\
& n(\%)\end{aligned}$ & $26(6.3)$ & $73(6.2)$ & 0.9424 \\
\hline
\end{tabular}


Table 1 (Continued)

\begin{tabular}{|c|c|c|c|}
\hline$n$ & IDDVT $(n=412)$ & PDVT $(n=1,173)$ & $p$ \\
\hline Fondaparinux $n$ & 9 & 31 & \\
\hline $\begin{array}{l}\text { Duration (mo) } \\
\text { Median (IQR) }\end{array}$ & $2.8(0.9-6.5)^{a}$ & $6.9(3.1-12.8)$ & \\
\hline $\begin{array}{l}\text { - Warfarin } \\
n(\%)\end{array}$ & $185(44.9)$ & $381(32.5)$ & $<0.0001$ \\
\hline $\begin{array}{l}\text { Duration (mo) } \\
\text { Median (IQR) }\end{array}$ & $9.6(4.3-23.1)$ & $14.5(6.8-26.3)$ & \\
\hline $\begin{array}{l}\text { - DOACs } \\
n(\%)\end{array}$ & $201(48.8)$ & $719(61.3)$ & $<0.0001$ \\
\hline $\begin{array}{l}\text { Duration (mo) } \\
\text { Median (IQR) }\end{array}$ & $5.6(3.1-9.7)^{b}$ & $8.7(4.7-15.9)$ & \\
\hline Apixaban $n$ ( $n$. low dose) & $38(6)$ & $157(33)$ & \\
\hline Dabigatran $n$ (n. low dose) & $28(3)$ & $72(10)$ & \\
\hline Edoxaban $n$ (n. low dose) & $15(1)$ & $55(17)$ & \\
\hline Rivaroxaban $n$ ( $n$. low dose) & $120(0)$ & $435(24)$ & \\
\hline
\end{tabular}

Abbreviations: $\mathrm{BMI}$, body mass index; $\mathrm{CrCl}$, creatinine clearance; CVD, cerebrovascular disease; DOACs, direct oral anticoagulants; IDDVT, isolated distal deep vein thrombosis; IHD, ischemic heart disease; IQR, interquartile range; LMWH, low molecular weight heparin; PAD, peripheral artery disease; PDVT, proximal deep vein thrombosis; RFs, risk factors; VTE, venous thromboembolism.

${ }^{a}$ The duration of treatment with parenteral drugs was significantly shorter than that with warfarin or DOACs $(p<0.0001)$.

${ }^{\mathrm{b}}$ The duration of treatment with DOACs was significantly shorter than that with Warfarin $(p=0.0103)$.

180 days, whereas the large majority $(>70 \%)$ received anticoagulation for $>180$ days. Among IDDVT patients, males were treated longer than women, with only $38 \%$ of them being treated for up to 90 days versus $62 \%$ of women. Patients with an unprovoked event received anticoagulation for $>180$ days (70.5\%). More patients, anticoagulated with warfarin, were treated for $>180$ days, as well as the patients with known thrombophilic alterations. Since it was plausible to expect that the use of DOACs for VTE indication, starting in our country on 2014, could have affected the results of treatment of patients, we performed a subanalysis of treatment characteristics in IDDVT patients by comparing those included between 2010 and $2014(n=208)$ or between 2015 and $2018(n=204)$. The VKAs use dropped from 77.4 to $11.3 \%$ $(p<0.0001)$, whereas DOACs increased from 20.7 to $78 \%$ $(p<0.0001)$; at the same time, the median duration of treatment lowered from 8.7 months (IQR: $4.4-23.4$ ) to 4.9 months (IQR: $3.0-9.1 ; p<0.0001$ ). Similar results were found also in patients with PDVT.

During treatment (-Table 3), 21 (5.6\% patient/years) bleeding events (either major or clinically relevant nonmajor) occurred in IDDVT and 38 (2.8\% patient/years) in PDVT patients $(p=0.0082)$. In both groups, the incidence of bleeding events was higher (though not statistically significant) in patients receiving warfarin (4.2\% patient/years) than DOACs (2.6\% patient/years, $p=0.0717$ ); it was significantly higher in IDDVT than PDVT patients who received warfarin $(p=0.0228)$. Four $(1.1 \%$ patient-years $)$ thrombotic events occurred during treatment in IDDVT and 32 (2.4\% patientyears) in PDVT patients (not significant). The incidence of thrombotic complications was similar in IDDVT or PDVT warfarin-treated patients (1.3 vs. $0.9 \%$ patient/years, respectively), and lower, though still not statistically significant, in DOAC-treated IDDVT versus PDVT patients (0.7 vs. $3.2 \%$ patient/years, respectively). Bleeding and thrombotic complications occurred more frequently late during treatment in both groups of patients. Taking the two groups together, $66.1 \%$ of bleeds and $86.1 \%$ of thrombotic complications occurred after 90 days of anticoagulant treatment

The cumulative occurrence of bleeding (Panel A) and thrombotic (Panel B) complications during treatment are shown in - Fig. 2. The hazard ratio (HR) of bleeding events in IDDVT versus PDVT was 1.87 (95\% CI: $1.02-3.43$ ); the incidence of thrombotic events was not significantly different between the two groups.

\section{Discussion}

Important results of the study are (1) the large majority of IDDVT patients received anticoagulation for more than the 3 months suggested by international guidelines; furthermore, more than half of them were anticoagulated for $>180$ days, a therapeutic decision taken more frequently in males when the event was unprovoked, patients with known thrombophilic conditions, and patients treated with warfarin; (2) such a long period of anticoagulation was associated with a nonnegligible occurrence of complications, especially bleeding (more than $70 \%$ of all bleeds occurred after the first 90 days of treatment); (3) the use of DOACs instead of VKAs for anticoagulation therapy in IDDVT patients increased sharply from 20.7\% (during the period 2010-2014) to 78\% (during 2015-2018) and was associated with a significant reduction of median duration of treatment (from 8.7-4.9 months). 
Table 2 Distribution of treatment duration in patients with IDDVT or PDVT in relation to the anticoagulant drug used and characteristics of IDDVT patients

\begin{tabular}{|c|c|c|c|c|}
\hline $\begin{array}{l}\text { Duration of anticoagulation } \\
n(\%)\end{array}$ & $\leq 90$ days & $91-180$ days & $>180$ days & $p$ \\
\hline IDDVT patients & $92(22.3)$ & $103(25.0)$ & $217(52.7)$ & \multirow[t]{4}{*}{$<0.0001$} \\
\hline LMWH-treated $(n=26)$ & 13 & 6 & 7 & \\
\hline VKA-treated $(n=185)$ & 33 & 36 & 116 & \\
\hline DOAC-treated $(n=201)$ & 46 & 61 & 94 & \\
\hline PDVT patients & $144(12.3)$ & $200(17.0)$ & $829(70.7)$ & \multirow[t]{4}{*}{$<0.0001$} \\
\hline LMWH-treated $(n=73)$ & 18 & 13 & 42 & \\
\hline VKA-treated, $(n=381)$ & 34 & 43 & 304 & \\
\hline DOAC-treated $(n=719)$ & 92 & 144 & 483 & \\
\hline \multicolumn{5}{|l|}{ Characteristics of IDDVT patients } \\
\hline Males & $35(38.0)$ & $45(43.7)$ & $125(57.6)$ & 0.0026 \\
\hline Females & $57(62.0)$ & $58(56.3)$ & $92(42.4)$ & \\
\hline \multicolumn{5}{|l|}{ Nature of index events } \\
\hline Unprovoked & $50(54.3)$ & $58(56.3)$ & $153(70.5)$ & \multirow[t]{2}{*}{0.0258} \\
\hline Provoked (weak and transient RFs) & $34(37.0)$ & $33(32.0)$ & $49(22.6)$ & \\
\hline Cancer or other permanent RFs & $8(8.7)$ & $12(11.7)$ & $15(6.9)$ & 0.3636 \\
\hline \multicolumn{5}{|l|}{ Age $(y)$} \\
\hline$<60$ & $37(40.2)$ & $41(39.8)$ & $84(38.7)$ & \multirow[t]{2}{*}{0.9631} \\
\hline$\geq 60$ & $55(59.8)$ & $62(60.2)$ & $133(61.3)$ & \\
\hline \multicolumn{5}{|l|}{ First available $\mathrm{CrCl}(\mathrm{mL} / \mathrm{min})$} \\
\hline$<60$ & $23(25.0)$ & $22(21.4)$ & $46(21.2)$ & 0.7464 \\
\hline$\geq 60$ & $69(75.0)$ & $81(78.6)$ & $171(78.8)$ & \\
\hline \multicolumn{5}{|l|}{ BMI $\left(\mathrm{kg} / \mathrm{m}^{2}\right)$} \\
\hline$\leq 25$ & $35(38.0)$ & $38(36.9)$ & $69(31.8)$ & \multirow[t]{3}{*}{0.4742} \\
\hline $26-30$ & $45(49.0)$ & $49(47.6)$ & $103(47.5)$ & \\
\hline$>30$ & $12(13.0)$ & $16(15.5)$ & $25(20.7)$ & \\
\hline Fragile (age $>75$ years, or $\geq 50 \mathrm{~kg}$, or $\mathrm{CrCl}<50$ ) & $35(38.0)$ & $26(25.2)$ & $61(28.1)$ & 0.1156 \\
\hline Diabetes & $8(8.7)$ & $5(4.9)$ & $22(10.1)$ & 0.2844 \\
\hline IHD, CVD, PAD & $7(7.6)$ & $19(18.4)$ & $34(15.7)$ & 0.0806 \\
\hline Heart failure & $3(3.3)$ & $3(2.9)$ & $5(2.3)$ & 0.8787 \\
\hline Chronic inflammatory diseases & $11(12.0)$ & $7(6.8)$ & $26(12.0)$ & 0.3377 \\
\hline Known thrombophilia & $2(2.2)$ & $4(3.9)$ & $27(12.4)$ & 0.0020 \\
\hline \multicolumn{5}{|l|}{ Anticoagulant drug used } \\
\hline LMWH/Fondaparinux & $13(14.1)$ & $6(5.8)$ & $7(3.2)$ & \multirow[t]{3}{*}{0.0001} \\
\hline Warfarin & $33(35.9)$ & $36(35.0)$ & $116(53.5)$ & \\
\hline DOACs & $46(50.0)$ & $61(59.2)$ & $94(43.3)$ & \\
\hline
\end{tabular}

Abbreviations: BMI, body mass index; $\mathrm{CrCl}$, creatinine clearance; CVD, cerebrovascular disease; DOACs, direct oral anticoagulants; IDDVT, isolated distal deep vein thrombosis; IHD, ischemic heart disease; LMWH, low molecular weight heparin; PAD, peripheral artery disease; PDVT, proximal deep vein thrombosis; RFs, risk factors.

Note: Statistically significant $p$-values $(<0.05)$ are depicted in bold

We were surprised to see how long Italian physicians treat patients with a first IDDVT episode with anticoagulants. Only a minority of these patients (22\%) were treated for a maximum of 3 months, whereas more than half received extended treatment. Albeit with some differences, recent international studies seem to support the view that giving long anticoagulant treatment to IDDVT patients is a growing trend, not limited to Italian physicians. Ageno \& Co. ${ }^{11}$ found that only $27.1 \%$ of IDDVT patients included in the prospective XALIA study had a treatment duration of up to 90 days, 
Table 3 Bleeding and thrombotic complications occurred during treatment in patients with IDDVT or PDVT

\begin{tabular}{|c|c|c|c|c|c|}
\hline & \multicolumn{2}{|c|}{ IDDVT n. 412} & \multicolumn{3}{|c|}{ PDVT n. 1173} \\
\hline Total follow-up (y) & \multicolumn{2}{|l|}{376} & \multicolumn{3}{|l|}{1352} \\
\hline Median FU (IQR) in months & \multicolumn{2}{|c|}{$6.2(3.2-15.6)$} & \multicolumn{3}{|c|}{$10.0(5.4-19.5)^{a}$} \\
\hline $\begin{array}{l}\text { Major and CRNMB } \\
n \text { (\% patient-years) }\end{array}$ & \multicolumn{2}{|c|}{$21(5.6)$} & \multicolumn{3}{|c|}{$38(2.8)^{\mathrm{b}}$} \\
\hline LMWHs/fondaparinux & \multicolumn{2}{|l|}{0} & \multicolumn{3}{|l|}{$3(5.1)$} \\
\hline Warfarin & \multicolumn{2}{|l|}{$15(6.8)$} & \multicolumn{3}{|l|}{$19(3.2)^{c}$} \\
\hline DOACs & \multicolumn{2}{|l|}{$6(4.3)$} & \multicolumn{3}{|l|}{$16(2.2)$} \\
\hline \multicolumn{6}{|l|}{$\begin{array}{l}\text { Timing of bleeding events } \\
n \text { (\% patient-years) }\end{array}$} \\
\hline$\leq 90$ days $($ IDDVT $=11 \mathrm{y} ;$ PDVT $=17 \mathrm{y})$ & \multicolumn{2}{|l|}{$6(54.5)$} & \multicolumn{3}{|l|}{$14(82.3)$} \\
\hline 91-180 (IDDVT = $35 \mathrm{y} ;$ PDVT $=68 \mathrm{y})$ & \multicolumn{2}{|l|}{$6(17.1)$} & \multicolumn{3}{|l|}{$5(7.3)$} \\
\hline$>180($ IDDVT $=220 \mathrm{y} ;$ PDVT $=1,209 \mathrm{y})$ & \multicolumn{2}{|l|}{$9(4.1)$} & \multicolumn{3}{|l|}{$19(1.6)$} \\
\hline Site of bleeds $(n)$ & Warfarin & DOACs & LMWHs & Warfarin & DOACs \\
\hline $\mathrm{ICH}$ & - & 1 & - & 1 & - \\
\hline $\mathrm{GIH}$ & 1 & 2 & 2 & 1 & 2 \\
\hline Other & 14 & 3 & 1 & 17 & 14 \\
\hline $\begin{array}{l}\text { Thrombotic events } \\
n \text { (\% patient-years) }\end{array}$ & \multicolumn{2}{|l|}{$4(1.1)$} & \multicolumn{3}{|l|}{$32(2.4)$} \\
\hline LMWH/fondaparinux & \multicolumn{2}{|l|}{0} & \multicolumn{3}{|l|}{$4(6.9)$} \\
\hline Warfarin & \multicolumn{2}{|l|}{$3(1.3)$} & \multicolumn{3}{|l|}{$5(0.9)$} \\
\hline DOACs & \multicolumn{2}{|l|}{$1(0.7)$} & \multicolumn{3}{|l|}{$23(3.2)$} \\
\hline \multicolumn{6}{|l|}{$\begin{array}{l}\text { Timing of thrombotic events } \\
n \text { (\% patient-years) }\end{array}$} \\
\hline$\leq 90$ days $($ IDDVT $=11 \mathrm{y} ;$ PDVT $=17 \mathrm{y})$ & \multicolumn{2}{|l|}{-} & \multicolumn{3}{|l|}{$5(29.4)$} \\
\hline $91-180($ IDDVT $=35 \mathrm{y} ;$ PDVT $=68 \mathrm{y})$ & - & & $3(4.4)$ & & \\
\hline$>180($ IDDVT $=220 \mathrm{y} ;$ PDVT $=1,209 \mathrm{y})$ & $4(1.8)$ & & $24(2.0)$ & & \\
\hline Type of thrombotic events & Warfarin & DOACs & LMWHs & Warfarin & DOACS \\
\hline Venous & 1 & - & 4 & 5 & 20 \\
\hline Arterial & 2 & 1 & - & - & 3 \\
\hline $\begin{array}{l}\text { Deaths during follow-up } \\
n(\%)\end{array}$ & $13(3.1)$ & & $82(7.0)$ & & \\
\hline Cancer, IHD, other (n) & $6,3,4$ & & $28,10,44$ & & \\
\hline $\begin{array}{l}\text { Lost to follow-up } \\
n(\%)\end{array}$ & $4(1.0)$ & & $9(0.8)$ & & \\
\hline
\end{tabular}

Abbreviations: CRNMB, clinically relevant non-major bleeding; DOACs, direct oral anticoagulants; FU, follow-up; GIH, gastrointestinal hemorrhage; ICH, intracranial hemorrhage; IDDVT, isolated distal deep vein thrombosis; IHD, ischemic heart disease; IQR, interquartile range; LMWH, low molecular weight heparin; PDVT, proximal deep vein thrombosis; y, years.

${ }^{a}$ The median duration of follow-up was significantly longer for PDVT than IDDVT patients $(p<0.0001)$.

'The bleeding incidence was higher in IDDVT than in PDVT patients $(p=0.0082)$.

${ }^{\mathrm{C}}$ The bleeding incidence was higher in IDDVT than PDVT warfarin treated patients $(p=0.0228)$.

whereas $27.9 \%$ of them were treated for $>180$ days. Schellong \& Co. $^{12}$ analyzed IDDVT patients who were included in the prospective GARFIELD-VTE study and found that $60 \%$ of them were anticoagulated at 6 months of follow-up and $40 \%$ at 12 months of follow-up.

Certainly, IDDVT is a condition that has long been object of debate. $^{3}$ Since the natural history of IDDVT is still uncertain and the risks associated with it not clearly quantified, even the need to test for distal DVT in patients with suspected DVT after exclusion of PDVT remains a matter of debate, with different approaches taken in clinical practice. ${ }^{13}$ It was clearly shown that IDDVT is associated with a lower risk of recurrence than PDVT or PE, ${ }^{14-17}$ while most untreated IDDVT have a benign clinical course with only some of them having clinically relevant thrombotic outcomes. ${ }^{18}$ Moreover, the two studies ${ }^{19,20}$ that randomized symptomatic patients to two different diagnostic procedures, allowing and not allowing diagnosis (and treatment) of IDDVT, 


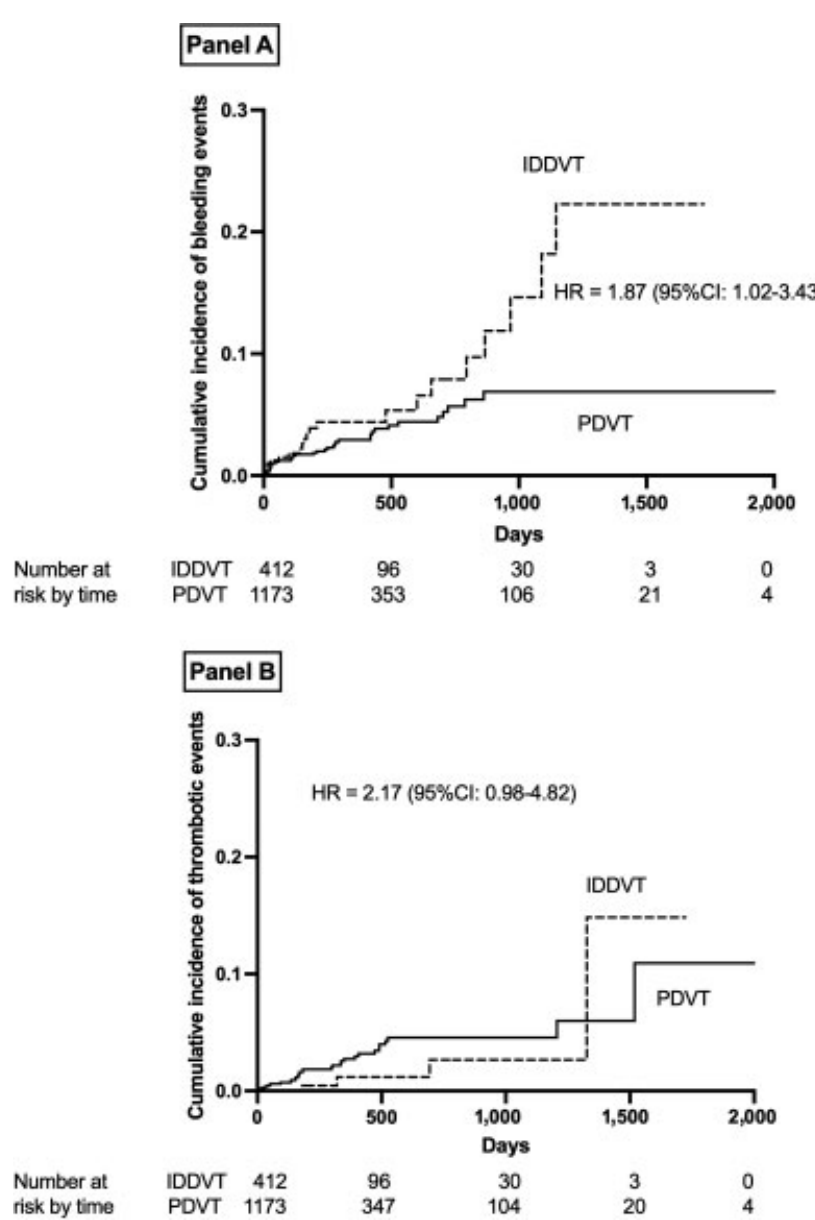

Fig. 2 Cumulative occurrence of bleeding (Panel A) and thrombotic (Panel B) events in patients with isolated distal (IDDVT) or proximal (PDVT) deep vein thrombosis. $\mathrm{Cl}$, confidence interval; $\mathrm{HR}$, hazard ratio.

concluded that the two strategies provided similar results in terms of thrombotic complications after 3 months of followup, thus proving it was not necessary to diagnose (and treat) IDDVT. Although these and other data clearly question the need to test for distal DVT, ${ }^{21}$ after IDDVTs are diagnosed the issue of their optimal treatment emerges, and especially how long anticoagulation therapy should last. In fact, a shorter duration of anticoagulation in these patients is a crucial point to lower the risk of bleeding, necessarily associated with anticoagulation, found in the present and other studies. ${ }^{22}$ Too short anticoagulation treatments, such as 4 to 6 weeks, offered inadequate protection against recurrence. ${ }^{23}$ International guidelines ${ }^{13}$ and experts ${ }^{24}$ have recommended 3 months of anticoagulation for IDDVT patients (the same duration recommended for patients with proximal DVT and/or PE) without extension of treatment.

Despite these recommendations, the present and other real-life studies (mentioned above) clearly show that there is a general trend lengthen anticoagulation treatment periods, not only for unprovoked major venous thrombotic events (such as proximal DVT and/or PE) but also for less serious events such as IDDVT. Today clinicians seem less inclined to set optimal duration periods for anticoagulation of VTE patients based on the balance between thrombotic risk and potential side effects of a long-lasting treatment. The reasons for this trend are many. First of all, deciding on how long anticoagulation should last in each patient is still a complex and far from easy issue to resolve for physicians; furthermore, the time and resources physicians and clinical centers have at their disposal for this task have been steadily declining in recent years, at least in our country. Many physicians and clinical centers prefer (or are forced by conditions) to continue treatment instead of calling in patients for a visit to decide whether it is preferable to stop anticoagulation or not. Some clinicians fear recurrence if anticoagulants are withdrawn and feel confident that currently available anticoagulants are safe enough to continue treatment indefinitely. An example of the effects of resource limitation can be seen in our results where IDDVT patients treated with warfarin had the longest period of treatment. The majority of these patients were managed by START-participants who work in anticoagulation clinics. In current working conditions, it is much easier for managing physicians to stick to their usual routine work (INR control and next dose prescription) than to try and fix an appointment for a possible stop therapy, inform the patient about the need for this step, find a space and a doctor available for a visit, etc. In this way, treatments are continued, and possible discontinuation of therapy simply not taken into consideration which clearly is a problem of organization and resources. The situation is different with DOAC use in Italy, since the National Health Service still requires a prescription in every 12 months (or 6 months for VTE in some regions) if the drugs are to be reimbursable. It is likely, therefore that VTE patients will receive DOAC treatment for periods of 6 or 12 months, or multiples. Our study shows that after their introduction for VTE treatment in 2014, the use of DOACs has rapidly increased in our country up to almost completely replace VKAs. Interestingly, DOACs use was associated with a marked reduction in the duration of anticoagulation treatment.

Other interesting results in our study are mentioned hereinafter. In keeping with previous reports, ${ }^{25-28}$ we found a trend for more bleeding complications in both distal and proximal DVT patients treated with warfarin than with DOACs. Among the patients treated with warfarin, bleeding events were significantly more frequent in IDDVT than in PDVT patients. It is well known that the bleeding risk with warfarin is higher during the first months of treatment, ${ }^{29}$ our finding can therefore be attributed to the shorter therapy in IDDVT than PDVT patients. Whatever the drug used, our study showed that many bleeding complications occurred late in treatment ( $>90$ days), a finding that would seem to discourage extending anticoagulation in subjects who are not at high risk of recurrence. Furthermore, all the few thrombotic events involving IDDVT patients and the majority of those in proximal DVT patients occurred late during treatment ( $>180$ days). In our opinion, this finding, which is in line with what we have recently published in patients with venous thromboembolism, ${ }^{30}$ has little to do with the efficacy of the drugs, but mainly to patients not adhering as well to treatment. The result highlights the importance of regular periodic visits during extended therapy in DOAC-treated patients to hammer home the need to stick to therapy and to lower the occurrence of late treatment failure. 


\section{Limitations}

The study has limitations. There is a large difference among the number and observation period of the two investigated groups of patients. All the data analyzed were collected in a prospective observational registry in which all the therapeutic decisions were left to the attending physicians. During the time interval of the study, there was a progressive increase of DOACs prescription, with a changing proportion of VKAtreated patients over time, a fact that may have been a confounder. Finally, during the study, it was impossible to collect data on the adherence of DOAC-treated patients to the prescribed therapeutic regimens; the persistence to treatment, however, was confirmed.

\section{Conclusion}

In conclusion, we found that the large majority of IDDVT patients received anticoagulation for more than the first 3 months after the event ( $>50 \%$ of patients received anticoagulant treatment for $>180$ days). This long treatment, which is in contrast with current recommendations in international guidelines, was associated with bleeding events ( $>70 \%$ of all bleeds occurred after the first 90 days of treatment) and also thrombotic complications during anticoagulation. These results lead us to comment that the standard 3 months anticoagulation period seem to be indicated for the majority of IDDVT patients. Specifically designed prospective studies are needed to assess the balance between the risks associated with an extended treatment beyond 90 days in these patients and the potential advantages on the rate of recurrences after anticoagulation is stopped.

\section{What Is Known on This Topic}

- The presence of an isolated distal deep vein thrombosis (IDDVT) is frequent in suspected DVT patients; however, its natural history, the associated clinical risks, and the optimal treatment are still uncertain.

- International guidelines recommend not more than 3 months of anticoagulation in patients with IDDVT.

- Which is the physicians' practice in real-life conditions in our country is not known.

\section{What Does This Paper Add}

- From the observational, prospective, multicenter START-Register, we examined 412 patients included for a first isolated distal deep vein thrombosis (IDDVT) event and compared with 1,173 patients with a first proximal DVT.

- The large majority of IDDVT patients received anticoagulation for more than the recommended 3 months, and more than half for more than 6 months.

- Most bleeding and thrombotic complications occurred late during treatment.

\section{Funding}

The Arianna Anticoagulation Foundation promotes and supports the START-Register, including the present study. The authors do not disclose receipt of the financial support for the research, authorship, and/or publication of this article.

\section{Conflict of Interest}

The authors declare no potential conflicts of interest with respect to the research, authorship, and/or publication of this article.

G.P. reports consulting fees from Alfasigma SpA.

\section{Acknowledgements}

\section{List of participating Centre}

The following Investigators and Centers participated to the START-Register and the FADOI-START-Register, and contributed to the present study

\section{START-Register}

Sophie Testa, Oriana Paoletti, UO Laboratorio Analisi, Centro Emostasi e Trombosi A O Istituti Ospitalieri di Cremona, Cremona;

Giuliana Guazzaloca, Benilde Cosmi, UO di Angiologia e Malattie Coagulazione, AOU S. Orsola-Malpighi, Bologna, Bologna;

Daniela Poli, Rossella Marcucci, Niccolò Maggini SOD Malattie Aterotrombotiche, Azienda Ospedaliero Universitaria-Careggi, Firenze

Vittorio Pengo, Dipartimento di Scienze Cardio-ToracoVascolari, Centro Trombosi, AOU Padova, Padova;

Anna Falanga, Teresa Lerede, USC SIMT, Centro Emostasi e Trombosi, Ospedale Papa Giovanni XXIII, Bergamo; Lucia Ruocco, Paolo Chiarugi, U.O. Analisi ChimicoCliniche, Azienda Ospedaliero Universitaria Pisana, Pisa; Giuliana Martini, Centro Emostasi, Spedali Civili Di Brescia, Brescia;

Simona Pedrini, Federica Bertola, Servizio di Laboratorio, Istituto Ospedaliero Fondazione Poliambulanza Brescia;

Lucilla Masciocco, Pasquale Saracino, Angelo Benvenuto, UOC Medicina Interna, Centro Controllo Coagulazione, Presidio Ospedaliero Lastaria, Lucera (Foggia); Claudio Vasselli, Laboratorio Patologia Clinica, Policlinico Casilino, Roma;

Pasquale Pignatelli, Daniele Pastori Centro Trombosi, Clinica Medica Policlinico Umberto I’, Università la Sapienza Roma

Elvira Grandone, Centro Trombosi Casa del Sollievo e della Sofferenza, S.Giovanni Rotondo (Foggia)

Marco Marzolo, UOC Medicina Interna, Ospedale di Rovigo

Mauro Pinelli, Daniela Mastroiacovo UOSD Angiologia e Diagnostica Vascolare, Ospedale SS Filippo e Nicola, Avezzano (L'Aquila)

Walter Ageno, Giovanna Colombo, UO. Medicina I, Ospedale di Circolo, Varese 
Eugenio Bucherini, SS Az.le di Angiologia Faenza (RA) AUSL Romagna;

Domizio Serra, Centro Trombosi, Ospedale Evangelico Internazionale, Genova

Andrea Toma, Pietro Barbera, UOC di Patologia Clinica, Ambulatorio Terapia Anticoagulante Orale, O.C. "L.Cazzavillan" Arzignano, (Vicenza);

Carmelo Paparo, Patologia Clinica, Ospedale Maggiore Chieri (Torino);

Antonio Insana, SC Patologia Clinica, Ospedale Santa Croce Moncalieri, Moncalieri (Torino);

Serena Rupoli, Clinica Ematologica, AOU- Ospedali Riuniti Ancona, Ancona;

Giuseppe Malcangi, Centro Emofilia e Trombosi,

Policlinico di Bari, Bari;

Maddalena Loredana Zighetti, SIMT- AO San Paolo, Milano;

Catello Mangione, Sezione Trasfusionale Ospedale di Galatina, Galatina (Lecce)

Domenico Lione, UOC Patologia Clinica, Ospedale

Perrino, Brindisi

Antonietta Piana, Francesco Cibecchini, Centro Prevenzione e Cura Malattie Tromboemboliche Azienda Ospedaliera Universitaria San Martino-IST, Genova;

Paola Casasco Servizio Medicina Trasfusionale Tortona (Alessandria);

Giovanni Nante, UOS Geriatria ULSS 16 Padova, Padova Alberto Tosetto, Divisione di Ematologia, Ospedale San Bortolo, Vicenza

Vincenzo Oriana Centro Emofilia - Presidio Ospedaliero Morelli- Reggio Calabria

Nicola Lucio Liberato, UO Medicina Interna Ospedale di Casorate Primo, Pavia

\section{FADOI-START}

Giancarlo Antonucci, Medicina Critica Ospedale Galliera, Genova

Giuseppina Bitti, Medicina Interna Ospedale Civile di Fermo, Fermo (Ancona)

Pier Giorgio Cavallo, UO medicina Interna Ospedale di Voghera (PV)

Stefano Cuppini, Medicina Interna Ospedale di Rovigo Lucrezia De Feudis, UOC Medicina Ospedale Santo Spirito Pescara

Francesco Dentali, Medicina Interna II, Ospedale di Circolo Varese, Varese

Riccardo Gerloni, Dipartimento di Medicina d'urgenza, Azienda Sanitaria Universitaria Integrata di Trieste

Michele Giacò, UO Geriatria Ospedale Renzetti Lanciano (Chieti)

Davide Grassi, UOC Medicina Interna P.O. L'Aquila

Davide Imberti, Medicina Interna Piacenza

Micaela La Regina, SC Medicina Interna 1 PO unico del Levante Ligure, La Spezia

Daniela Mastroiacovo, UOSD Angiologia Ospedale di Avezzano

Vincenzo Menditto, Medicina D'urgenza- Ospedali Riuniti Marche, Ancona
Francesca Mete, Medicina Interna Ospedale di Rivoli (Torino)

Rino Migliacci, Medicina Interna Ospedale di Cortona Nicola Mumoli, UOS Dipartimentale di Diagnostica Vascolare, Ospedale di Livorno

Federico Pasin, Dipartimento di Medicina Ospedale di Cremona

Raffaele Pesavento, UO Clinica Medica 3 Azienda

Ospedaliero Universitaria Padova

Michela Provisione, Ospedale Medicina 2 Ospedale Busto Arsizio (Varese)

Piero Pujatti, UO Medicina Ospedale Arzignano(Vicenza) Roberta Re, Medicina Interna 2, Ospedale Maggiore della Carità Novara

Sabina Villalta, Medicina Interna Ospedale di Treviso

\section{References}

1 Palareti G, Agnelli G, Imberti D, et al; MASTER Investigators. Do Italian vascular centers look for isolated calf deep vein thrombosis? Analysis of isolated calf deep vein thromboses included in the "Master" Registry. Int Angiol 2008;27(06):482-488

2 Palareti G, Schellong S. Isolated distal deep vein thrombosis: what we know and what we are doing.J Thromb Haemost 2012;10(01):11-19

3 Palareti G. How I treat isolated distal deep vein thrombosis (IDDVT). Blood 2014;123(12):1802-1809

4 Barco S. What's the matter with distal deep vein thrombosis? Thromb Haemost 2019;119(10):1547-1549

5 Antonucci E, Poli D, Tosetto A, et al; START-Register. The Italian START-Register on anticoagulation with focus on atrial fibrillation. PLoS One 2015;10(05):e0124719

6 von Elm E, Altman DG, Egger M, Pocock SJ, Gøtzsche PC, Vandenbroucke JPSTROBE Initiative. The Strengthening the Reporting of Observational Studies in Epidemiology (STROBE) statement: guidelines for reporting observational studies. Ann Intern Med 2007;147(08):573-577

7 Cockcroft DW, Gault MH. Prediction of creatinine clearance from serum creatinine. Nephron 1976;16(01):31-41

8 National Kidney Foundation. K/DOQI clinical practice guidelines for chronic kidney disease: evaluation, classification, and stratification. Am J Kidney Dis 2002;39(02, Suppl 1):S1-S266

9 Schulman S, Kearon CSubcommittee on Control of Anticoagulation of the Scientific and Standardization Committee of the International Society on Thrombosis and Haemostasis. Definition of major bleeding in clinical investigations of antihemostatic medicinal products in non-surgical patients. J Thromb Haemost 2005;3(04):692-694

10 Kaatz S, Ahmad D, Spyropoulos AC, Schulman SSubcommittee on Control of Anticoagulation. Definition of clinically relevant nonmajor bleeding in studies of anticoagulants in atrial fibrillation and venous thromboembolic disease in non-surgical patients: communication from the SSC of the ISTH. J Thromb Haemost 2015;13(11):2119-2126

11 Ageno W, Mantovani LG, Haas S, et al. Patient management strategies and long-term outcomes in isolated distal deep-vein thrombosis versus proximal deep-vein thrombosis: findings from XALIA. TH Open 2019;3(01):e85-e93

12 Schellong SM, Goldhaber SZ, Weitz JI, et al. Isolated distal deep vein thrombosis: perspectives from the GARFIELD-VTE Registry. Thromb Haemost 2019;119(10):1675-1685

13 Kearon C, Akl EA, Ornelas J, et al. Antithrombotic therapy for VTE disease: CHEST guideline and expert panel report. Chest 2016; 149(02):315-352

14 Schulman S, Rhedin AS, Lindmarker P, et al; Duration of Anticoagulation Trial Study Group. A comparison of six weeks with 
six months of oral anticoagulant therapy after a first episode of venous thromboembolism. N Engl J Med 1995;332(25):1661-1665

15 Pinede L, Ninet J, Duhaut P, et al; Investigators of the "Durée Optimale du Traitement AntiVitamines K" (DOTAVK) Study. Comparison of 3 and 6 months of oral anticoagulant therapy after a first episode of proximal deep vein thrombosis or pulmonary embolism and comparison of 6 and 12 weeks of therapy after isolated calf deep vein thrombosis. Circulation 2001;103(20):2453-2460

16 Galanaud JP, Quenet S, Rivron-Guillot K, et al; RIETE INVESTIGATORS. Comparison of the clinical history of symptomatic isolated distal deep-vein thrombosis vs. proximal deep vein thrombosis in 11086 patients. J Thromb Haemost 2009;7(12):2028-2034

17 Eichinger S, Heinze G, Jandeck LM, Kyrle PA. Risk assessment of recurrence in patients with unprovoked deep vein thrombosis or pulmonary embolism: the Vienna prediction model. Circulation 2010;121(14):1630-1636

18 Palareti G, Cosmi B, Lessiani G, et al. Evolution of untreated calf deep-vein thrombosis in high risk symptomatic outpatients: the blind, prospective CALTHRO study. Thromb Haemost 2010;104 (05):1063-1070

19 Bernardi E, Camporese G, Büller HR, et al; Erasmus Study Group. Serial 2-point ultrasonography plus D-dimer vs whole-leg colorcoded Doppler ultrasonography for diagnosing suspected symptomatic deep vein thrombosis: a randomized controlled trial. JAMA 2008;300(14):1653-1659

20 Gibson NS, Schellong SM, Kheir DY, et al. Safety and sensitivity of two ultrasound strategies in patients with clinically suspected deep venous thrombosis: a prospective management study. J Thromb Haemost 2009;7(12):2035-2041

21 Righini M, Paris S, Le Gal G, Laroche JP, Perrier A, Bounameaux H. Clinical relevance of distal deep vein thrombosis. Review of literature data. Thromb Haemost 2006;95(01):56-64
22 Utter GH, Dhillon TS, Salcedo ES, et al. Therapeutic anticoagulation for isolated calf deep vein thrombosis. JAMA Surg 2016;151 (09):e161770

23 Donadini MP, Dentali F, Pegoraro S, et al. Long-term recurrence of venous thromboembolism after short-term treatment of symptomatic isolated distal deep vein thrombosis: a cohort study. Vasc Med 2017;22(06):518-524

24 Kearon C, Kahn SR. Long-term treatment of venous thromboembolism. Blood 2020;135(05):317-325

25 Wu C, Alotaibi GS, Alsaleh K, Linkins LA, McMurtry MS. Case-fatality of recurrent venous thromboembolism and major bleeding associated with aspirin, warfarin, and direct oral anticoagulants for secondary prevention. Thromb Res 2015;135(02):243-248

26 Kolinsky DC, Schwarz ES. Are new oral anticoagulants safer than vitamin $\mathrm{k}$ antagonists in the treatment of venous thromboembolism? Ann Emerg Med 2016;67(04):455-457

27 Blann AD, Lip GY. Non-vitamin K antagonist oral anticoagulants (NOACs) for the management of venous thromboembolism. Heart 2016;102(12):975-983

28 Coleman CI, Bunz TJ, Turpie AGG. Effectiveness and safety of rivaroxaban versus warfarin for treatment and prevention of recurrence of venous thromboembolism. Thromb Haemost 2017;117(10):1841-1847

29 Palareti G, Leali N, Coccheri S, et al; Italian Study on Complications of Oral Anticoagulant Therapy. Bleeding complications of oral anticoagulant treatment: an inception-cohort, prospective collaborative study (ISCOAT). Lancet 1996;348(9025):423-428

30 Palareti G, Antonucci E, Legnani C, et al; START2 Register Investigators. Bleeding and thrombotic complications during treatment with direct oral anticoagulants or vitamin $\mathrm{K}$ antagonists in venous thromboembolic patients included in the prospective, observational START2-register. BMJ Open 2020;10(11):e040449 